\title{
A renúncia de patente sobre vacinas COVID é certa e justa
}

\author{
Éber Coelho Paraguassu (1) e Anneli Celis Mercedes de Cardenas (2)
}

\section{EDITORIAL}

Cada país deve ter o direito de fazer suas próprias vacinas durante uma pandemia. Esse é o princípio que sustenta a campanha para renunciar temporariamente à proteção da propriedade intelectual (PI) nas vacinas contra o coronavírus. A campanha foi iniciada pela Índia e África do Sul e está sendo apoiada por mais de 100 países, juntamente com organizações internacionais, incluindo a Organização Mundial da Saúde e a instituição de caridade das Nações Unidas para a AIDS, UNAIDS. O objetivo é reduzir as barreiras para os países que produzem suas próprias vacinas - principalmente para as de renda mais baixa.

Atualmente, a proposta não conta com o apoio da indústria farmacêutica, nem da maioria das nações de alta renda. Em vez disso, esses países estão se comprometendo a compartilhar mais de suas próprias vacinas com nações de baixa renda e a fornecer mais financiamento para esquemas de provisão de vacinas de caridade, como o COVAX. No entanto, em um movimento surpreendente e bem-vindo no início deste mês, os Estados Unidos, a Rússia e a China se manifestaram em apoio a uma isenção de IP para vacinas.

A importância da decisão dos EUA em particular não pode ser exagerada, porque o país é o maior mercado mundial de produtos farmacêuticos. Durante décadas, os governos dos EUA trabalharam com a indústria, universidades e outras nações com intensa pesquisa na definição - e aplicação - das regras de PI, mais recentemente por meio da Organização Mundial do Comércio (OMC), onde a proposta de isenção de $\mathrm{PI}$ está sendo discutida. Mesmo há alguns meses, a mera ideia de os Estados Unidos tomarem essa posição seria impensável. Agora que isso aconteceu, os países que ainda resistem notadamente Japão, Coréia do Sul, Reino Unido e Estados membros da União Europeia precisam seguir o exemplo. 


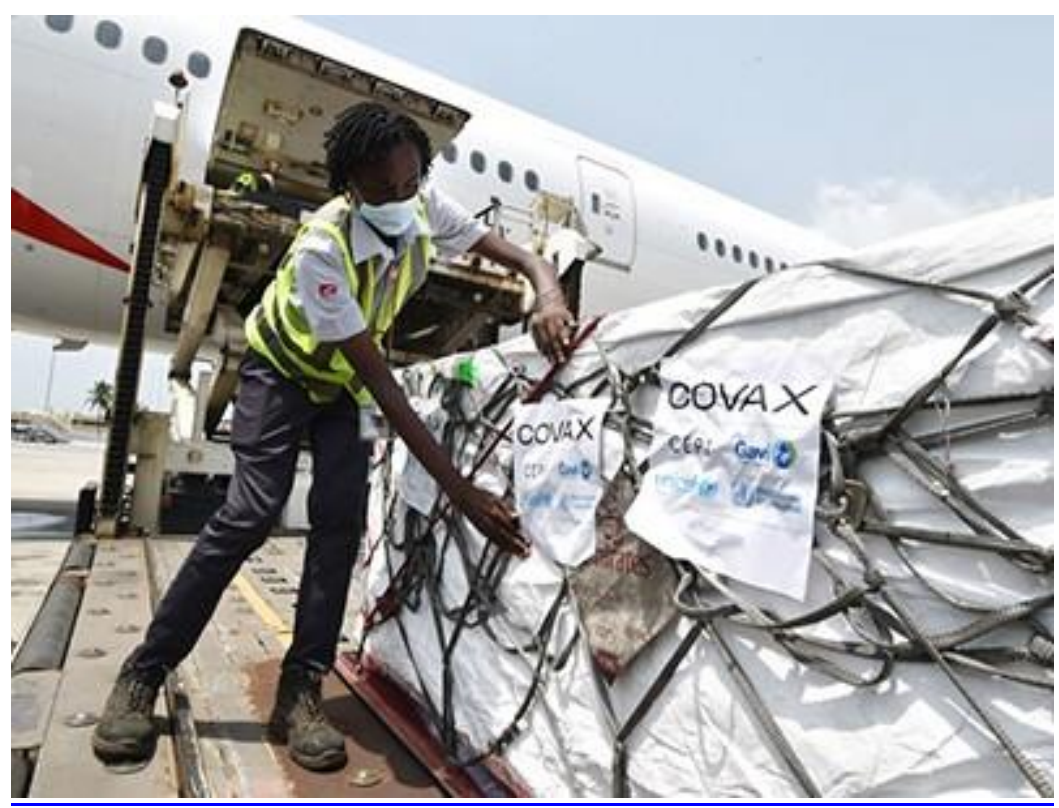

https://www.nature.com/articles/d41586-021-01048-1

Uma das maiores preocupações sobre as isenções de IP é que elas fornecem um atalho para concorrentes que buscam adquirir tecnologia cara. As empresas também dizem que o alívio da PI não vai acelerar a fabricação de vacinas, porque os materiais são escassos e pode levar vários anos para construir a capacidade do zero.

Além disso, os governos que se opõem à isenção argumentam que as regras atuais da OMC já permitem que os países solicitem 'licença compulsória' para anular a PI durante emergências. Neste momento, por exemplo, a Bolívia está se candidatando à OMC para usar esse processo para permitir a fabricação da vacina COVID da Johnson \& Johnson. No entanto, um grupo de pesquisadores no Reino Unido que estuda a lei de patentes aponta em um documento preliminar sobre a proposta de isenção de que as licenças compulsórias são extremamente complexas e demoradas para solicitar.

A UE também assinalou que os Estados Unidos têm bloqueado as exportações de vacinas COVID-19 e seus componentes. É certo que isso seja chamado. $\mathrm{O}$ abrandamento de tais restrições é essencial em uma pandemia.

Esses são argumentos importantes e precisam ser abordados. Mas eles não são, em si mesmos, motivos para negar o alívio de PI. No mínimo, à medida que a pandemia avança, os motivos para permitir uma renúncia ficam mais fortes.

O problema central é que a fabricação, a pesquisa e o desenvolvimento de vacinas estão muito concentrados em um pequeno grupo de países de renda alta e média. As empresas nesses países, que também são as principais detentoras de $\mathrm{Pl}$, venderam a maioria das doses de vacinas disponíveis para seus próprios governos e para governos de outras nações de alta renda. Cerca de 6 bilhões de doses das 8,6 bilhões de compras 
confirmadas até agora foram pré-encomendadas por governos de países de renda alta e média.

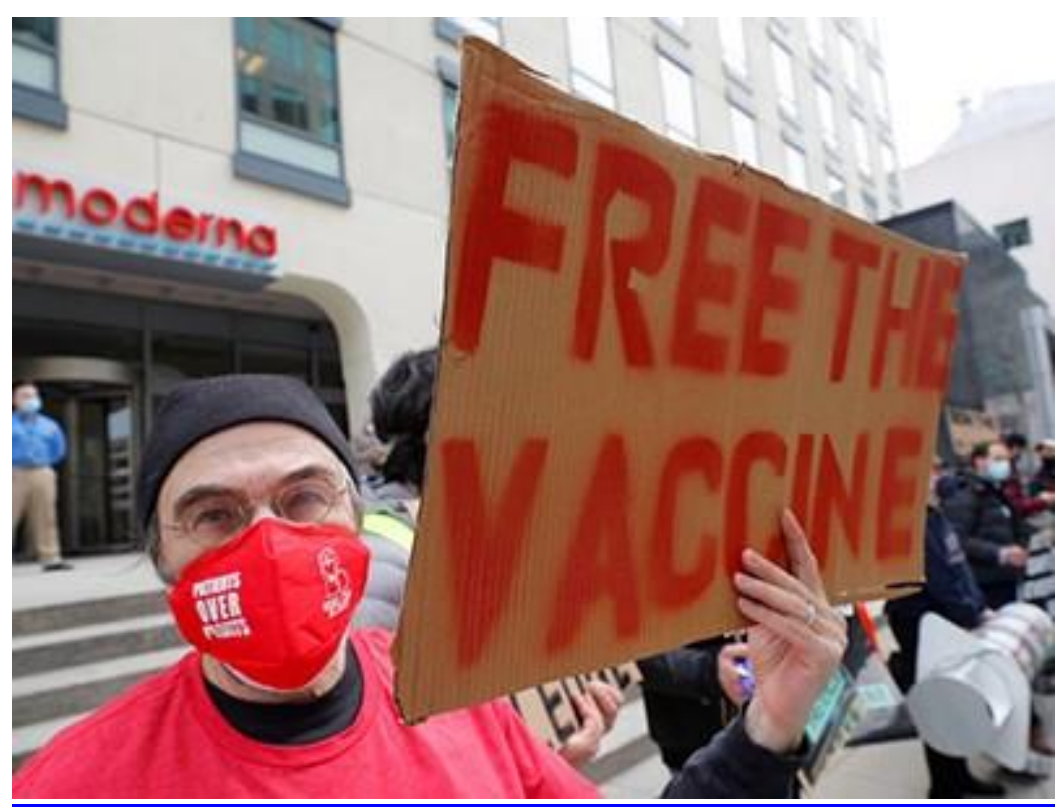

https://www.nature.com/articles/d41586-021-00863-w

De acordo com dados da indústria farmacêutica, a indústria espera ter feito um total de cerca de dez bilhões de doses de vacina até o final de 2021. Mas com base nas tendências atuais, é improvável que isso aconteça, de acordo com pesquisadores do Fundo Monetário Internacional em Washington DC. Em um artigo publicado em 19 de maio, eles relataram que a indústria provavelmente terá produzido cerca de seis bilhões de doses até o final de 2021. Esse déficit potencial aumenta o risco de que as pessoas em países de baixa renda precisem esperar ainda mais pelas primeiras doses.

De acordo com a publicação da Nature, o número de vacinas administradas até agora na África era de pouco mais de uma dose por pessoa para cerca de $2 \%$ dos 1,2 bilhão de habitantes da África. Entre outros fatores, isso ocorre porque o continente importa atualmente $99 \%$ de suas vacinas e porque os países africanos não têm capacidade de compra antecipada de nações mais ricas. É por isso que a União Africana anunciou um plano para 60\% das vacinas da África a serem fabricadas no continente até 2040.

Na Cúpula Global de Saúde em Roma na semana passada, antes da Assembleia Mundial da Saúde desta semana em Genebra, Suíça, as nações europeias prometeram compartilhar mais doses de vacinas com países de baixa e média renda. A presidente da Comissão Europeia, Ursula von der Leyen, também propõe 'esclarecer e simplificar' as formas existentes em que os países podem implementar o licenciamento compulsório. $E$ há uma grande possibilidade de que o grupo G7 das maiores economias do mundo prometa mais financiamento para a vacinação quando os países membros se reunirem no Reino Unido no próximo mês. 
Esses compromissos são cruciais na corrida para acabar com a pandemia. Mas eles não lidam com a questão sistêmica - os países que apoiam a isenção de PI não estão pedindo caridade, mas o direito de desenvolver e fazer suas próprias vacinas, sem a preocupação de serem processados pelos detentores de patentes.

Aqueles que apoiam a isenção de IP COVID entende este princípio básico. Os líderes de países que atualmente não são a favor da dispensa de patente também devem reconhecê-la. Como diz John Nkengasong, diretor dos Centros Africanos para Controle e Prevenção de Doenças: eles precisam estar do lado certo quando a história da pandemia vier a ser escrita.

Instituição afiliada: 1- Specialized Dentistry Group. 2- Departamento de Ciencias da Saúde, Universidade Federal do Amapá.

Dados da publicação: Artigo recebido em 10 de junho, revisado em 15 de junho, aceito para publicação em 20 de junho e publicado em 30 de junho.

DOI: https://doi.org/10.36557/2674-8169.2021v3n6p01-05

Éber Coelo Paraguassu miromj@humv.es

This work is licensed under a Creative Commons Attribution 4.0

International License.

\section{REFERÊNCIAS}

1. Nature. Disponivel em: https://www.nature.com/articles/d41586-021$\underline{00863-w}$

2. Nature. Disponovel em: https://www.nature.com/articles/d41586-021$\underline{01048-1}$

3. Coelho Paraguassu, E. ., H. . Chen, F. . Zhou, Z. . Xu, e M. . Wang. "Coronavirus and COVID-19: The Latest News and Views from the Scientific Community about the New Coronavirus and COVID-19.". Brazilian Journal of Implantology and Health Sciences, vol. 2, no 3, março de 2020, p. 96-109, doi:10.36557/2674-8169.2020v2n3p96-109.

4. Lemos, P. ., N. . de Almeida Filho, e J. Firmo. "COVID-19, Desastre Do Sistema De Saúde No Presente E tragédia Da Economia Em Um Futuro Bem próximo.". Brazilian Journal of Implantology and Health Sciences, vol. 2, no 4, abril de 2020, p. 39-50, doi:10.36557/2674- 
8169.2020v2n4p39-50.

5. Coelho Paraguassu, E. ., e A. M. . Celis de Cárdenas. "Estudos Atuais Sobre Medicamentos Para Combater a COVID-19.". Brazilian Journal of Implantology and Health Sciences, vol. 2, no 11, outubro de 2020, p. 0109, doi:10.36557/2674-8169.2020v2n11p01-09.

6. Coelho Paraguassu, E. ., A. M. . Celis de Cardenas, R. . Ferreira de Andrade, C. . La Vecchia, e L. . Naldi. "The Covid-19 Explosion in the State of Amapá: How Is the Most Preserved Region in the Brazilian Amazon Currently Fighting the SARS-COV 2 Pandemic?". Brazilian Journal of Implantology and Health Sciences, vol. 2, no 5, maio de 2020, p. 3-11, doi:10.36557/2674-8169.2020v2n5p3-11.

7. Coelho Paraguassu, E. . "COVID-19, a relação Direta Entre O Capital, Solidariedade E As Vidas.". Brazilian Journal of Implantology and Health Sciences , vol. 2, no 3, março de 2020, p. 01-04, https://bjihs.emnuvens.com.br/bjihs/article/view/33. 